\title{
O planejamento da expansão urbana na interface com a urbanização dispersa: uma análise sobre a região metropolitana de Campinas (1970-2006)
}

\author{
The planning of urban sprawl in the interface with the scattered urbanization: \\ an analysis of the metropolitan area of Campinas (1970-2006)
}

Sidney Piochi Bernardini

Universidade Estadual de Campinas (UNICAMP), Faculdade de Engenharia Civil, Arquitetura e Urbanismo, Campinas, SP, Brasil

\section{Resumo}

A Região Metropolitana de Campinas, localizada no quadrante sudeste do Estado de São Paulo, possui uma configuração territorial tratada pela literatura como um caso emblemático da chamada urbanização dispersa. Para evidenciar esse processo e verificar de que forma os seus municípios lidaram com esse fenômeno, este artigo pretende iluminar o processo de construção do aparato planificador e legal instituído entre 1970 e 2006. 0 método, de caráter quantitativo e analítico, baseou-se na investigação e sistematização dos planos e dispositivos correlatos que possuíam interface com a questão da expansão urbana, analisando as relações entre as diretrizes traçadas e os mecanismos incluídos nas leis. Os resultados evidenciaram que as diretrizes não tiveram efetividade na determinação da lógica de expansão urbana, especialmente nas décadas de 1970 e 1980, quando a urbanização foi mais intensa e a atuação dos poderes públicos foi mais incremental. Ainda que os municípios tenham mantido instrumentos ambíguos em relação à transformação de áreas rurais em urbanas, foi possível notar uma sensível mudança na sua constituição, principalmente a partir da década de 1990, com uma diminuição de leis de alteração de perímetros urbanos e o aumento de restrições ambientais que podem ter contribuído para refrear o processo de dispersão.

Palavras-chave: Expansão urbana. Urbanização. Legislação urbanística. Região metropolitana de Campinas.

\section{Abstract}

The Metropolitan Area of Campinas, situated in the southeast quadrant of the state of São Paulo, has a specific territorial configuration described by the literature as a typical case of the so-called sprawling urbanization. To provide evidence of this process and verify how the municipalities have dealt with this phenomenon, this paper focused on the legal and planning apparatus instituted between 1970 and 2006. The method featured by quantitative and analytic procedures was based on a research of the master plans and the urban legislation followed by the systematization of provisions related to the urban sprawl issue, analyzing the relationship between the settled guidelines and the legal self-regulatory arrangements. The results showed that the guidelines were not as effective as expected regarding the planning of urban sprawl, mainly in the 1970s and 1980s when the process of urbanization was intensified and the actions of public authorities were more incremental. Although the municipalities maintained ambiguous procedures over the transformation from rural to urban areas, it

SPB é arquiteto e urbanista; doutor em arquitetura e urbanismo, e-mail: sidpiochi@fec.unicamp.br 
was possible to perceive a sensible change in the legal arrangements, mainly since the 1990s when the laws on alteration of urban perimeters were reduced and environmental provisions increased, which may have contributed to curb the dispersion process.

Keywords: Urban sprawl. Urbanization. Urban legislation. Metropolitan area of Campinas.

\section{Introdução}

A compreensão da dinâmica de crescimento das cidades do ponto de vista físico-territorial vem desafiando a prática científica nas últimas décadas. Com o aumento das taxas de urbanização em praticamente todo o mundo, a primazia do meio urbano sobre o rural, conforme já apontou Lefebvre (1971), tornou-se mais evidente e já não pode mais ser contestada. A questão que se coloca é se esse crescimento pode ser planejado. 0 aumento da população nas cidades e sua resultante espacial pode denotar, a princípio, um inevitável aumento da "mancha" urbanizada em novos loteamentos e novos subúrbios. A questão, entretanto, é menos simples do que parece e não tem necessariamente a ver somente com as tendências desse crescimento populacional e o arranjo das suas densidades na área urbanizada.

Seja qual for a explicação que se dê para o fenômeno e o tipo de configuração ou forma resultante de sua dinâmica, os impactos da expansão urbana já têm sido apontados. 0 clássico artigo de Frumkin (2002), denominado Urban Sprawl and Public Health, publicado na revista Public Health Reports, já apontava para os efeitos negativos do sprawling, observando, a partir da relação entre densidade populacional e número de viagens por automóveis, os impactos nos números de acidentes, no sedentarismo da população e na qualidade do ar e da água. Dois relatórios publicados, o primeiro pela Universidade de Ottawa, de 2013, e o segundo por Litman (2015), comprovam e quantificam estes impactos em termos de custos. 0 segundo relatório indica que o sprawling nos Estados Unidos compromete mais de 400 bilhões de dólares anuais em custos externos e 625 bilhões de dólares em custos internos. Os estudos sobre a urbanização contemporânea no Brasil vêm se intensificando, com destaque para os trabalhos coordenados por Reis (2006), que investiga a chamada "urbanização dispersa", fenômeno que ele cunhou a partir de uma rede de pesquisas por todo o Brasil e que identifica essa nova forma de organização espacial relacionada com esse ambiente produtivo. Embora constate que suas pesquisas se voltam para as características dos tecidos urbanos surgidos nos últimos vinte anos, o autor enfatiza a perspectiva histórica de longa duração para analisar o fenômeno, considerando que estas mudanças nos padrões urbanísticos são partes de um processo mais amplo que passou a ocorrer ao longo da segunda metade do século XX, sumarizados em algumas características específicas (Reis, 2006, p. 49). Estas mudanças ocorrem por uma série de fatores: a adoção de novos modos de vida da população, que adquire maior mobilidade; a adoção de modalidades complexas de gestão dos espaços urbanos (condomínios e loteamentos fechados); alterações nas relações entre espaços públicos e privados; novas formas de organização do mercado imobiliário com a adoção de projetos urbanísticos específicos.

Em corroboração a estas constatações, a Região Metropolitana de Campinas tem sido apontada, em pesquisas recentes, como um caso emblemático da chamada urbanização dispersa. Pretende-se com este artigo iluminar o processo de construção do aparato planificador e legal que se instituiu isoladamente em cada um dos municípios pertencentes a essa região, relacionados à questão da expansão urbana, entre os anos de 1970 e 2006 e sua natureza ante a esse fenômeno de dispersão. Diante de um intenso processo de urbanização que se sucedeu nestas décadas, a pesquisa pretende elucidar de que forma trabalharam essa institucionalização e como ela evoluiu ao longo do tempo, buscando observar se houve avanços do ponto de vista da gestão desse processo.

No início da década de 1970, pari passu a um processo de industrialização, modernização das atividades agropecuárias articuladas à indústria, a serviços e ao aumento das taxas de crescimento populacional (Cano \& Brandão, 2002) que se manifestaram na maior parte dos municípios que formariam, em 2000, a Região Metropolitana de Campinas, vários deles iniciaram a elaboração de planos diretores 
de desenvolvimento integrado em atendimento às prerrogativas do SERFHAU (Serviço Federal de Habitação e Urbanismo), que, em 1967, por força da Lei Federal no 4.380 (Vizioli, 1998), passaria a ter um papel mais incisivo no apoio ao planejamento urbano municipal. A sequência de instrumentos legais urbanísticos que se instituíram a partir desse momento revela a conduta destes municípios com suas práticas de gestão frente ao processo de expansão urbana que se acelerou nesta década. Em 2006, quando boa parte dos municípios deveriam, por força da Lei Federal no 10.270 , de 10 de julho de 2001, ter novos planos diretores concluídos e promulgados, dois aspectos poderiam ser reveladores de uma mudança no âmbito destas condutas planificadoras, embora dicotômicos: uma maior articulação nas decisões em face a nova organização regional com a instituição da região metropolitana por lei, ao lado de um poder mais incisivo de cada ente municipal com a adoção de instrumentos urbanísticos específicos para o enfrentamento do fenômeno.

\section{Notas metodológicas}

As explicações sobre as novas relações produtivas pós-fordistas (Harvey, 2004) complementada pelas análises de Soja (2000), para as novas formas espaciais, e de Reis (2006), no tocante à chamada urbanização dispersa, orientaram a composição metodológica desta pesquisa.

O método, de caráter quantitativo e analítico, baseou-se na investigação de planos e documentos legais urbanísticos no período estabelecido. No âmbito dos procedimentos, foram definidos dois momentos - um primeiro voltado para o levantamento documental e um segundo dedicado à sua seleção e análise. Como se tratava de um longo período e de um grande conjunto de documentos, optou-se por estabelecer uma análise mais quantitativa (estatística) no primeiro momento, para se chegar a uma mais "qualitativa" no segundo, quando os planos e leis que tinham direta ou indiretamente alguma interferência na questão da expansão urbana foram sistematizados.

A sistematização foi realizada por município, o que possibilitou desenvolver uma análise comparativa entre cada um e, na segunda etapa, a organização dos conteúdos, também por localidade, possibilitou evidenciar os aspectos comuns existentes nos mecanismos planificadores e legais estabelecidos, incluindo formas de delimitação dos perímetros urbanos, definição de polígonos de expansão urbana isolados e tipos de disposição que induziram a dispersão dos tecidos urbanos.

\section{A dispersão territorial da região metropolitana de Campinas}

Situada na porção sudeste do Estado de São Paulo, a Região Metropolitana de Campinas, que reunia, até 2014, 19 municípios, foi criada pelo governo estadual pela Lei no 870, de 19 de junho de 2000 (São Paulo, 2000), apresentando desde a sua criação algumas características espaciais peculiares, dada a presença de grandes glebas não ocupadas de características rurais e uma nucleação urbana com baixas densidades populacionais (Nascimento, 2013). Campinas, a sede da região, já possuía uma proeminência no cenário estadual no auge do período cafeeiro, ao possibilitar por sua relevante posição geográfica o cruzamento das principais companhias ferroviárias, a Companhia Mogiana e a Companhia Paulista, que ligavam as muitas localidades nos vetores norte e noroeste do Estado. Este cruzamento foi capaz de atender à produção e exportação do café do Oeste paulista e do Triângulo e do sul de mineiros (Pedroso, 2002). A inversão de um modelo agroexportador, centrado não só nesta região, mas em todo o Estado de São Paulo, para uma economia industrial alterou a sua fisionomia já a partir da década de 1930 (Cano, 2012).

Mesmo com todo o seu desenvolvimento, Campinas não se constituiu como um polo estruturador de uma rede urbana nas décadas subsequentes, que se refletiu em um processo de expansão urbana tímido, assim como ocorreu com os demais municípios do seu entorno. A partir da década de 1970, entretanto, diante de uma nova fase da industrialização paulista, essa dinâmica se intensificou, mas não se alterou por completo, mesmo com uma acentuação do seu crescimento populacional e a acentuação do grau de interação entre os municípios. A transposição dos limites da cidade-sede passou a configurar um aglomerado urbano, identificado com as especificidades da dinâmica regional, e das relações entre alguns municípios em vinculação ao próprio desenvolvimento industrial para além de Campinas, no eixo da Via Anhanguera e de algumas rodovias. Segundo Pires (2007), a rede urbana no início da década de 1970 compreendia Campinas como polo regional e Americana, Valinhos, Indaiatuba 
e Santa Bárbara d'Oeste como localidades secundárias, contendo considerável diversidade econômica. Quase todos estes municípios já existiam nos anos 1940, quando uma série de desmembramentos ocorreram para formar as demais localidades até o início da década de 1970 (Nandin, 2013), em um conjunto de delimitações municipais próximas daquelas consideradas para a formação metropolitana. Quando desmembradas, estas ainda tinham o predomínio da população rural, cuja fisionomia se alteraria, já nos anos 1970, com sua articulação a essa dinâmica econômica. Todo o movimento de expansão que se sucedeu dessa configuração pode ser relacionado com os principais eixos rodoviários, que até o início da década de 1980 já estavam implantados.

Este processo de industrialização se intensificou justamente no contexto da interiorização do parque industrial paulista, observada por diversos autores (Azzoni, 1987; Gonçalves, 1994; Lencioni, 1994; Negri \& Pacheco, 1994; Pereira \& Sampaio, 1997). A Política Nacional de Desenvolvimento Urbano (PNDU), associada ao II Plano Nacional de Desenvolvimento (PND), em 1974, já reconhecia que Campinas, assim como Santos, no âmbito estadual, eram municípios que deveriam ser acompanhados por medidas de disciplinamento e controle, de forma a não comprometer suas bases produtivas (Souza, 2010). Ao lado destas transformações estruturais, o crescimento populacional foi expressivo, apresentando, para alguns municípios do entorno de Campinas, altas taxas de crescimento comparáveis àquelas que ocorreram na região de São Paulo em décadas anteriores, como pode ser observado na Tabela 1. Tal configuração foi consideravelmente maior entre as décadas de 1970 e 1980, tendo sido interpretada, inclusive, como um tradicional processo de "periferização", conforme ocorreu em outras metrópoles nacionais em períodos anteriores (Baeninger, 2001).

Tabela 1 - Taxa Geométrica de Crescimento Populacional em Campinas e nos municípios do entorno da Região Metropolitana (1970-2000)

\begin{tabular}{ccc}
\hline \multicolumn{3}{c}{ Taxa de Crescimento Geométrico Populacional (1970-2000) } \\
\hline Intervalos & Campinas & Entorno \\
\hline $1970-1980$ & 5,86 & 7,22 \\
$1980-1990$ & 2,22 & 4,73 \\
$1990-2000$ & 1,52 & 3,34 \\
\hline
\end{tabular}

População presente e residente por sexo - 1970 a 2010 . Fonte: Adaptado de IBGE (2017).
Isto pode ter muitos significados, mas o mais evidente é que essa urbanização, a partir de uma suposta industrialização "tardia" na maior parte dos municípios da região, foi concorrente de uma outra fonte de investimentos ligada a práticas reprodutivas do capital em novos empreendimentos imobiliários (Pires, 2007), combinando dispersão territorial e segregação socioespacial (Cunha, 2006). A região passou a ser palco de um novo modelo de urbanização, que teve o loteamento fechado e o condomínio horizontal como principais tipologias de assentamentos, principalmente nas últimas duas décadas, conforme demonstraram Caiado \& Pires (2006), Caiado (2006, 2007), Miranda (2002) e Freitas (2008), que apontaram para uma profusão destes tipos de empreendimentos também em áreas rurais. A implantação e reestruturação de vários eixos rodoviários de ligação entre os municípios (Figura 1) contribuiu para essa dispersão, conformando novas acessibilidades para além dos seus núcleos originais dessa configuração.

Não obstante esse grau de dispersão já fosse sintomático do modelo de ocupação que vinha ocorrendo nas décadas passadas, antes mesmo que seus municípios fossem agregados em uma entidade regional, ele não deve ser lido como um fenômeno perene, tampouco homogêneo. 0 trabalho desenvolvido por Mitica (2008), através de fotointerpretação da evolução das manchas urbanizadas a partir de imagens de satélite entre 1970 e 2000, constatou que, ao lado de um aumento crescente das áreas dos núcleos principais dos municípios, o total da área relativa dos núcleos dispersos por década foi diminuindo gradativamente. As manchas urbanizadas que se uniram de alguma forma aos núcleos centrais dos municípios cresceram linearmente entre as décadas de 1970 e 2000, superando em grande medida aquelas manchas que cresceram dispersas. Isto revela para o autor que a dispersão se constitui como um fenômeno transitório, mais intenso nos estágios iniciais, restituindo certa contiguidade dos tecidos urbanos, na medida em que estes vão se consolidando. 0 desenho do processo de expansão analisado por Nascimento (2016) reitera algumas destas considerações, observando também que a conurbação da região ainda é parcial, abrangendo os municípios mais populosos e com maiores taxas de urbanização, cuja conformação da mancha urbanizada se dá ao longo de alguns eixos rodoviários, como é o caso do complexo Anhanguera-Bandeirantes. A intensificação da ocupação com a implantação 


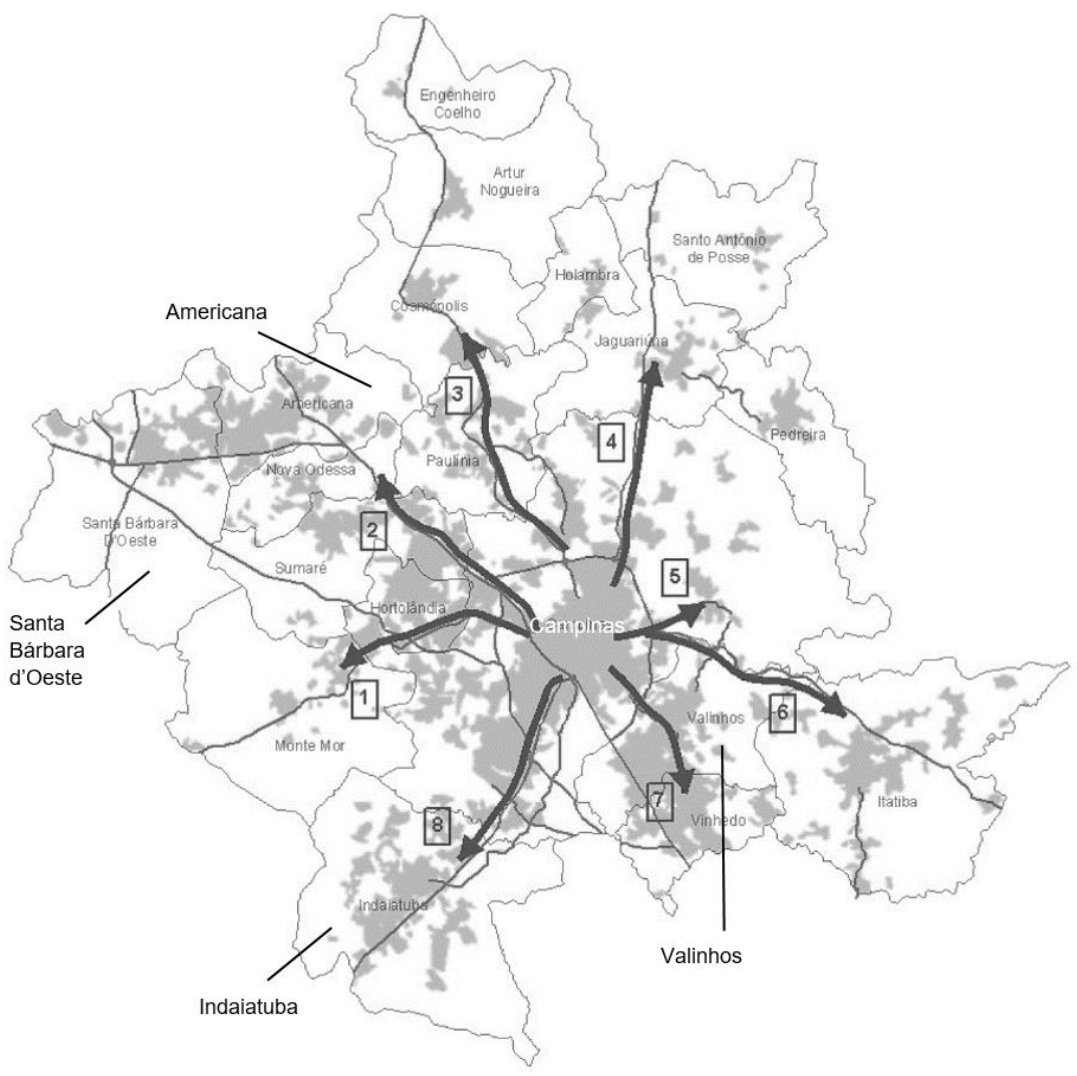

Legenda:

em 2000 Área urbanizada

Eixo 1: SP 101 -

Hortolândia e Monte

Mor

Eixo 2: Via Anhanguera

- Sumaré, Nova Odessa,

Americana e Santa

Bárbara

Eixo 3: SP 332 -

Paulínia, Cosmópolis, Artur Nogueira e Eng.

Coelho

Eixo 4: SP 340 -

Jaguariúna, Holambra e Santo Antônio da Posse

Eixo 5: Distritos de

Sousas e J. Egídio

Eixo 6: Rodovia D.

Pedro I - Valinhos e

Itatiba

Eixo 7: Via Anhanguera

- Valinhos e Vinhedo

Eixo 8: Rodovia Santos

Dumont-Indaiatuba

Figura 1 - Vetores de expansão urbana da Região Metropolitana de Campinas

Fonte: Adaptado de Prefeitura Municipal de Campinas (2006), com base em cartografia da EMPLASA.

destes empreendimentos se refletiu no expressivo aumento da área urbanizada, em especial até a década de 1990, contribuindo, é possível dizer, para essa conurbação parcial e concomitante diminuição do grau de dispersão, conforme pode ser visualizado na Figura 2. Entre 1965 e 2010, a área efetivamente ocupada passou de $173 \mathrm{~km}^{2}$ para $928 \mathrm{~km}^{2}$, e entre os anos de 1979 e 1989 a expansão foi mais veloz, quando as manchas urbanas começaram a se aproximar e as terras rurais entre elas passaram a ser suprimidas, no aguardo de novos empreendimentos futuros.

Nesta dicotomia entre dispersão/fragmentação e concentração/unificação dos tecidos urbanos, apontam-se várias indagações, já que tanto Mitica (2008) como Nascimento (2013) sugerem que a configuração das manchas urbanizadas, tal como está, é momentânea, apresentando uma clara tendência para uma configuração mais compacta. Mas se a velocidade dessa conurbação tem sido bem menor nas últimas décadas, e ainda de forma menos dispersa, é possível vislumbrar uma real contribuição das ações planejadas neste território nas últimas quatro décadas?

\section{Expansão urbana e perímetros urbanos: uma dicotomia proposital?}

As 295 leis que alteraram perímetros urbanos nos municípios da região entre 1970 e 2006 representam 9,56\% de todos os instrumentos (planos e leis urbanísticas) elaborados ou promulgados no período, conforme Tabela 2. Vale dizer que, mesmo considerando as rápidas mudanças de estratégias vinculadas às alterações constantes destes instrumentos, conforme se verá, supõe-se uma possível "instabilidade" na fixação dos polígonos das áreas urbanas ao longo dos 36 anos abarcados por esta pesquisa, e uma certa liberalidade dos poderes públicos na transformação de áreas rurais em urbanas em um processo de acelerado crescimento que ocorreu principalmente na década de 1970.

Estas alterações não ocorreram de forma distribuída pelas décadas, tampouco pelos municípios constituintes, podendo observar, também, a inexistência de uma setorização planejada dessa expansão para um 


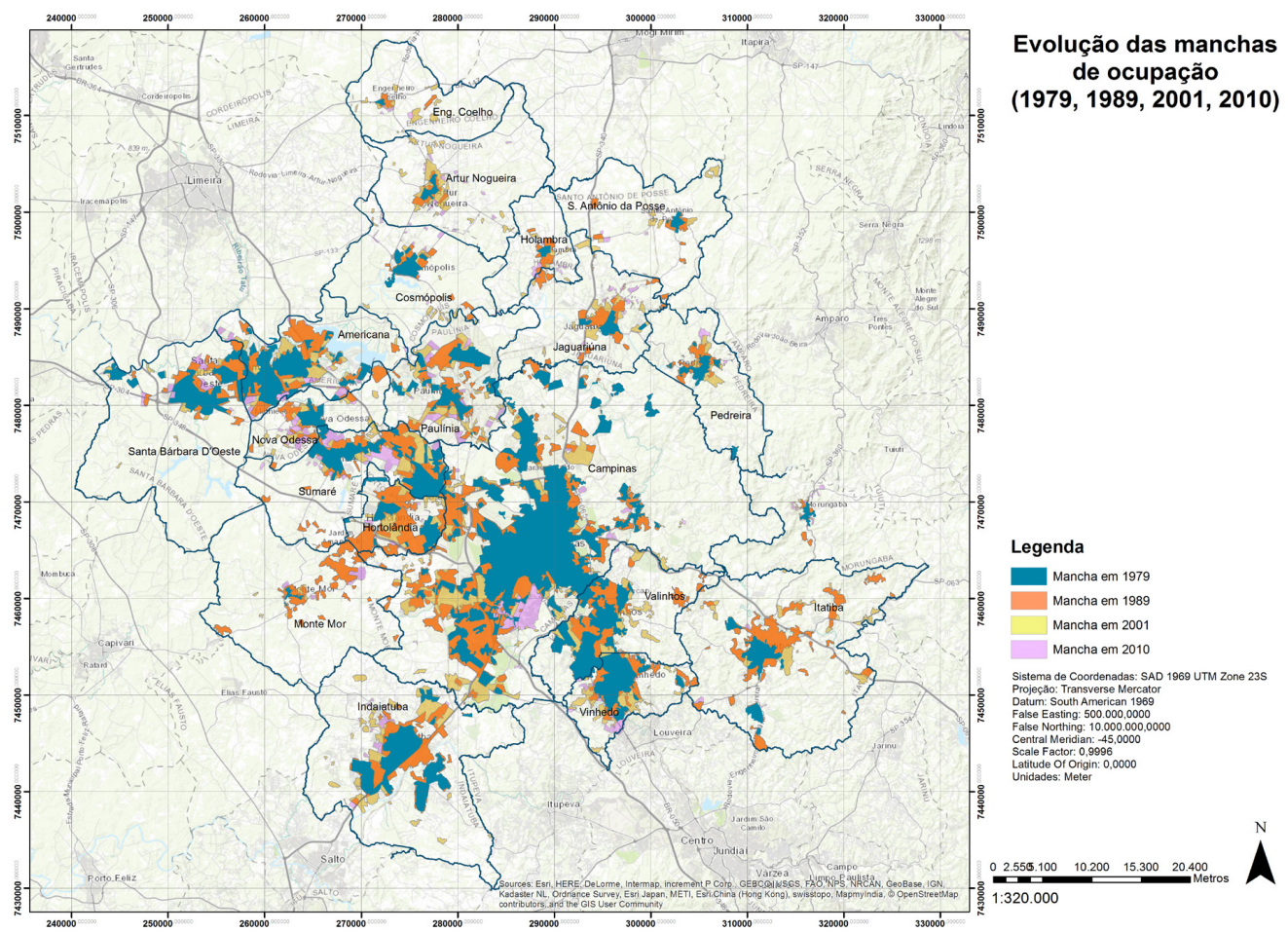

Figura 2 - Evolução da área urbanizada da Região Metropolitana de Campinas (1965-2010)

Fonte: Adaptado de Nascimento (2013, p. 81).

Tabela 2 - Leis de alteração de perímetro urbano dos municípios da Região Metropolitana de Campinas por década

\begin{tabular}{lccccc}
\hline \multicolumn{1}{c}{ Município } & $\mathbf{1 9 7 0}$ & $\mathbf{1 9 8 0}$ & $\mathbf{1 9 9 0}$ & $\mathbf{2 0 0 0}$ & Total \\
\hline Americana & 6 & 1 & 0 & 0 & 7 \\
Artur Nogueira & 4 & 3 & 7 & 0 & 14 \\
Campinas & 10 & 4 & 2 & 2 & 18 \\
Cosmópolis & 16 & 11 & 6 & 4 & 37 \\
Eng. Coelho & - & - & 1 & 0 & 1 \\
Holambra & - & - & 7 & 2 & 9 \\
Hortolândia & - & - & 0 & 1 & 1 \\
Indaiatuba & 2 & 0 & 4 & 1 & 7 \\
Itatiba & 6 & 7 & 9 & 16 & 38 \\
Jaguariúna & 8 & 5 & 7 & 1 & 21 \\
Monte Mor & 3 & 13 & 5 & 10 & 31 \\
Nova Odessa & 8 & 0 & 1 & 6 & 15 \\
Paulínia & 4 & 0 & 0 & 1 & 5 \\
Pedreira & 5 & 1 & 1 & 1 & 8 \\
Santa Bárbara & 7 & 0 & 1 & 1 & 9 \\
Santo Antônio & 5 & 1 & 1 & 1 & 8 \\
Sumaré & 9 & 2 & 1 & 0 & 12 \\
Valinhos & 34 & 6 & 5 & 1 & 46 \\
Vinhedo & 8 & 0 & 0 & 0 & 8 \\
Total & 136 & 54 & 55 & 44 & 295 \\
\hline
\end{tabular}

Fonte: Elaboração própria (2017). determinado quadrante, a considerar que os municípios que somam a maior quantidade de leis dessa natureza (Cosmópolis, Itatiba, Monte Mor e Valinhos) não fazem parte de um mesmo setor espacial nem são semelhantes em termos de tamanho populacional e área efetivamente ocupada. Supõe-se, aliás, que se estas alterações tiveram alguma efetividade no planejamento da expansão urbana, a abrangência territorial resultante era bem distinta, a saber pela forma das manchas expandidas em cada um destes municípios, como é possível observar no caso de Valinhos, com uma intensificação da expansão urbana após os anos 1970.

Outro aspecto que deve ser observado é abrangência territorial das leis, já que nem sempre elas definiram polígonos contíguos aos núcleos urbanizados ou definiam áreas urbanas muito extensas, às vezes quase coincidentes com o próprio perímetro do município, sobrepondo-se, portanto, às suas áreas rurais. 0 município de Itatiba, por exemplo, delimitou bairros isolados como áreas de expansão urbana nas diversas leis promulgadas. Em Sumaré, uma única lei, ainda na década de 1970 (Lei no 1.361/1977; Sumaré, 1977), estabeleceu 19 polígonos de expansão urbana, incluindo muitas glebas em áreas rurais isoladas. O caso de Monte Mor é ainda mais emblemático, 
já que a maioria das leis instituídas transformou um conjunto de glebas rurais isoladas em áreas de expansão urbana, o que parece ser bastante revelador do tipo de urbanização que se deu naquele município, cuja fragmentação em pequenas manchas dispersas, observadas principalmente no início da década de 1980 (ver Figura 1), é bem significativa ao lado de uma expansão um pouco mais contínua, porém bem menos expressiva a partir do seu núcleo original. No município de Hortolândia, que se emancipou de Sumaré em 1991, a primeira lei que alteraria o seu perímetro urbano, em 2000, estabeleceu um polígono perimetral e mais quatro zonas de expansão urbana que abrangiam quase $100 \%$ do território municipal, assim como em Americana, onde o polígono do perímetro urbano instituído no final da década de 1970 praticamente coincidia com o perímetro do município, deixando como rural apenas uma área isolada a leste.

Planos diretores e diretrizes de expansão urbana

Se a ideia de plano diretor teria certa proeminência no início da década de 1970, perderia força nos anos que se seguiam, só sendo retomada no início dos anos 1990, quando alguns municípios passaram a elaborar planos a partir de iniciativas espontâneas e, na década de 2000, por força da Lei Federal no 10.257/01 (Brasil, 2001). Desde a sua criação, a Região Metropolitana de Campinas passou a ter a Emplasa (Empresa Paulista de Planejamento Metropolitano) como principal órgão de planejamento, papel que essa empresa já exercia na Região Metropolitana de São Paulo. Em 2003, o governo estadual criou a Agemcamp (Agência Metropolitana de Campinas), um braço executivo da Emplasa, mas que não teve papel articulador na elaboração destes planos diretores pós-Estatuto da Cidade.

É possível enxergar com clareza três momentos da utilização do plano diretor pelos seus municípios, tendo sido instituídos 10 na década de 1970, 2 na década de 1980, 9 na década de 1990 e 21 na década de 2000, sem contar todas as revisões efetuadas. A Tabela 3 demonstra como se deu a relação entre estes planos e as leis de alteração de perímetros urbanos por município. Pode-se observar que a maioria teve planos diretores instituídos na década de 1970, o que revela, para estes casos, um planejamento anterior da expansão urbana. Seria válido dizer que, para estes, mesmo com a instituição de leis de alteração do perímetro urbano, teria havido maior preocupação com esse crescimento da área urbanizada. Neste conjunto, alguns municípios parecem ter sido menos ostensivos na delimitação de novos perímetros, como é o caso de Americana, Indaiatuba e Paulínia, que tiveram poucas alterações de polígonos após a promulgação dos planos.

Entretanto, Campinas, Nova Odessa, Santa Bárbara, Sumaré e Valinhos tiveram, ao contrário, mais alterações subsequentes em seus planos. Estes, com exceção de Nova Odessa, continuaram fazendo alterações nas décadas seguintes, mesmo sem ainda ter novos planos diretores instituídos, o que pode revelar uma desconsideração da lógica planificadora. Mesmo que estas alterações tenham sido feitas para adequar as áreas de expansão para efeitos de tributação, o descompasso entre os instrumentos chama a atenção. Os casos de Itatiba e Valinhos são emblemáticos nesse aspecto - o primeiro por estabelecer uma prática excessiva de revisões dos seus planos diretores, sempre seguidas de muitas alterações dos seus perímetros urbanos, e o segundo ao demonstrar a prática incisiva dessas modificações planimétricas claramente desvinculadas de alguma atitude mais restritiva de expansão urbana, já que tais alterações continuaram ocorrendo mesmo tendo passados mais de 10 anos da instituição do seu plano diretor.

Quanto aos casos de Americana, Campinas e Indaiatuba, que tiveram planos diretores elaborados com certo rigor técnico entre o final da década de 1960 e o início da de 1970, constatou-se que apenas para o primeiro município as alterações de perímetro seguiram as diretrizes de expansão urbana do plano diretor, de forma sucessiva até 1976, ainda que com relativa liberalidade, já que o polígono de expansão quase coincidia com o do município. Para os demais, entretanto, as alterações posteriores não foram exatamente coincidentes com o estabelecido nos planos respectivos. Em Campinas, a hipótese de expansão urbana escolhida como a mais provável, no vetor norte/nordeste já contrariava a tendência de expansão mais evidente no vetor oeste/sudoeste, que reunia a população de menor poder aquisitivo, e em Indaiatuba, a diretriz para expansão ao norte foi deliberadamente contrariada, em 1978, pela lei que 
Tabela 3 - Relação entre planos diretores aprovados e leis de alteração de perímetros urbanos

\begin{tabular}{|c|c|c|c|c|c|c|c|c|}
\hline \multirow[t]{2}{*}{ Municipio } & \multicolumn{2}{|c|}{ Década de 1970} & \multicolumn{2}{|c|}{ Década de 1980} & \multicolumn{2}{|c|}{ Década de 1990} & \multicolumn{2}{|c|}{ Década de 2000} \\
\hline & PD / Ano & PU & PD / Ano & $\mathrm{PU}$ & PD / Ano & $\mathrm{PU}$ & PD / Ano & PU \\
\hline Americana & $01 / 1970$ & 6 & & 1 & $01 / 1999$ & 0 & $01 / 2008$ & 0 \\
\hline Artur Nogueira & $01 / 1970$ & 4 & $01 / 1984$ & 3 & & 7 & 01 / 2007 & 0 \\
\hline Campinas & $01 / 1970$ & 10 & & 4 & 02 / 1991; 1996 & 2 & $01 / 2006$ & 2 \\
\hline Cosmópolis & & 16 & & 11 & & 6 & $01 / 2007$ & 4 \\
\hline Eng. Coelho & & & & & & 1 & $01 / 2006$ & 0 \\
\hline Holambra & & & & & & 7 & $01 / 2007$ & 2 \\
\hline Hortolândia & & & & & & 0 & $01 / 2008$ & 1 \\
\hline Indaiatuba & $01 / 1969$ & 2 & & 0 & & 5 & $01 / 2001$ & 0 \\
\hline Itatiba & 02 / 1970; 1976 & 6 & 02 / 1981; 1983 & 7 & $01 / 1996$ & 9 & 02 / 2000; 2004 & 16 \\
\hline Jaguariúna & & 8 & 02 / 1985; 1989 & 5 & 03 / 1996; 1999 & 7 & 01 / 2004 & 1 \\
\hline Monte Mor & & 3 & & 13 & $01 / 1992$ & 5 & $01 / 2006$ & 10 \\
\hline Nova Odessa & $01 / 1975$ & 8 & & 0 & & 1 & $01 / 2006$ & 6 \\
\hline Paulínia & $01 / 1970$ & 4 & & 0 & $01 / 1992$ & 0 & $01 / 2006$ & 1 \\
\hline Pedreira & & 5 & & 1 & & 1 & 02 / 2003; 2006 & 1 \\
\hline Santa Bárbara & $01 / 1972$ & 7 & $01 / 1983$ & 0 & & 1 & $01 / 2006$ & 1 \\
\hline Santo Antônio & & 5 & & 1 & 02 / 1991; 1995 & 1 & $01 / 2006$ & 1 \\
\hline Sumaré & $01 / 1972$ & 9 & & 2 & & 1 & $01 / 2006$ & 0 \\
\hline Valinhos & $01 / 1971$ & 34 & & 6 & & 5 & $01 / 2004$ & 1 \\
\hline Vinhedo & & 8 & $01 / 1984$ & 0 & & 0 & 01 / 2007 & 0 \\
\hline
\end{tabular}

Legenda: PD = plano diretor; PU = perímetro urbano. Fonte: Elaboração própria (2017).

fixou o novo perímetro urbano, acolhendo a tendência de expansão a oeste, que de fato ocorreu.

De outro lado, está um conjunto de municípios que não tiveram planos diretores instituídos na década de 1970 e que, ao mesmo tempo, tiveram muitas redefinições de perímetros urbanos ao longo das décadas. É o caso dos municípios de Cosmópolis, Jaguariúna, Monte Mor, Pedreira, Santo Antônio e Vinhedo. A quantidade significativa de leis de alteração de perímetro nestes municípios na década de 1970 reforça a ideia de uma desvinculação destas modificações a uma atitude planificadora desse período, questão que se modifica, apenas para alguns casos, de forma intempestiva, já na década de 1980, como em Jaguariúna e Vinhedo. Nesse mesmo grupo podem ser incluídos os municípios emancipados na década de 1990: Engenheiro Coelho, Holambra e Hortolândia, que herdaram de seus municípios de origem as respectivas leis perimétricas.
Considerando a fragilidade a que essa governança metropolitana se deu neste momento da elaboração dos novos planos diretores municipais da década de 2000, as questões comuns relacionadas ao planejamento da expansão urbana neste âmbito não foram mediadas pelas entidades estaduais, já que sua formulação se deu com total autonomia. É sintomático que somente em 2015 o governo federal brasileiro lançasse mão de uma lei que regesse a esfera metropolitana, denominada de Estatuto da Metrópole, adotando o conceito de governança interfederativa, que no Brasil reforçou o papel dos Estados brasileiros em detrimento da ampliação de estruturas de poder metropolitano que poderiam considerar, na agenda da governança, os movimentos que buscam maior coordenação e articulação entre escalas, agentes e interessados neste âmbito do território, como observou Klink (2010). 
Ambiguidades das normas urbanísticas: o rural e urbano na lógica da expansão urbana

A compreensão da dicotomia rural-urbano não transparece nas normas legais estabelecidas no período, já que a recorrência ao rural como espaço delimitado, tanto nos planos como nas demais leis urbanísticas, não veio acompanhada de argumentos incisivos para a sua permanência nos municípios. Se a imagem de um rural agrícola já era contraditória com as intenções de alguns prefeitos nos primeiros anos da década de 1970, com as oportunidades ligadas à industrialização e incorporação imobiliária, como observou Pires (2006), continuariam a sê-lo sob o manto legal nas décadas seguintes, com a manutenção dessa separação (urbano-rural) em muitos dos dispositivos presentes.

Diante da teia legislativa que se estabeleceu nos municípios da região entre 1970 e 2006, é possível perceber uma estrutura normativa complexa e difícil de ser apreendida de imediato. Uma análise atenta sobre os demais instrumentos de controle urbano, como as leis de uso, ocupação e parcelamento do solo, revela certa ambiguidade nas restrições de ocupação das áreas delimitadas como não urbanas. A adoção nos planos diretores das chamadas macrozonas ou zonas de expansão urbana, que via de regra lançam-se sobre áreas rurais (em conformidade com a legislação de perímetro urbano), tornando-se, portanto, áreas rurais passíveis de serem transformadas em urbanas, conforme se amplifique a necessidade de realizar essa expansão, nem sempre é tão evidente ou bem instrumentalizada diante do descompasso da instituição dos instrumentos legislativos. Além disso, a relação entre as leis de perímetros urbanos e as demais leis de controle urbano deveria também, a priori, guardar uma sintonia, de forma que estas respeitassem os limites estabelecidos pelas primeiras. Como essa legislação possui efeitos aplicativos no tocante à gestão do uso e ocupação do solo, muitas vezes não chegam a reverberar nas diretrizes de expansão urbana da política de ordenamento dos planos diretores, estabelecendo, além disso, dispositivos que extrapolam, pelas medidas adotadas, as restrições a ocupações determinadas. Se é possível notar que há uma vinculação entre alterações planimétricas dos perímetros com diretrizes de expansão urbana e zoneamento instituído em alguns casos, também se percebem subterfúgios utilizados como mecanismos legais que elevam a possibilidade de autorizar ocupações nas áreas rurais com a instituição de zonas de expansão urbana, algumas vezes desvinculadas dos planos diretores, deixando entrever uma lacuna na relação entre expansão urbana planejada (plano diretor), perímetro urbano e zoneamento (regras de uso e ocupação do solo), que no caso da Região Metropolitana de Campinas revela um incrementalismo acentuado, conforme se observa pelo excessivo número de instrumentos legais instituídos, indicando uma sinergia entre os poderes públicos locais, proprietários e empreendedores. Já no início da década de 1970, muitos loteamentos passaram a ser executados na região em áreas distantes das sedes urbanas e, muitas vezes, próximos a divisas municipais ou implantados em dois municípios contíguos. Quando a Lei Federal de Parcelamento do Solo, Lei no 6766/1979 (Brasil, 1979), foi promulgada, proibindo o parcelamento para fins urbanos em áreas rurais, essa situação já era corriqueira, segundo relatos de vários gestores municipais quando inquiridos sobre o processo de expansão urbana em seus municípios. A ambiguidade, entretanto, quanto aos dispositivos que se sobrepõem à divisão rural e urbana permaneceu após 1979, inclusive nos últimos planos diretores pós-Estatuto da Cidade.

O conjunto de dispositivos sistematizados a partir da leitura dos planos diretores, leis de uso, ocupação e parcelamento do solo demonstra uma ampla e complexa engrenagem para facilitar, ou pelo menos não obstruir, a ocupação urbana por parcelamento do solo ou condomínios em áreas rurais e implementação de novas instalações industriais, shopping centers e outras instalações do terciário avançado, ainda que a denominação do que pode ser considerado urbano não seja assim tão precisa, conforme pode ser observado na Tabela 4 . 0 conjunto mais significativo, como se há de notar, é aquele relacionado com o parcelamento do solo especial em áreas rurais, tomado pelo nome de "chácaras de recreio", denominação aliás recorrente na legislação de parcelamento do solo destes municípios, revelando a sua penetração como modelo alternativo ao parcelamento do solo em áreas urbanas ou de expansão urbana, segundo a Lei Federal no 6766/79. Assim também, essa modalidade continuou sendo empregada mesmo após a instituição da lei federal, recobrindo um imaginário que justifica a sua permanência, como figura que transforma glebas rurais em determinados tipos de loteamentos e que, 
Tabela 4 - Dispositivos utilizados na legislação urbanística dos municípios pertencentes à Região Metropolitana de Campinas relacionados com a ocupação em área rural

\begin{tabular}{|c|c|}
\hline Tipo de dispositivo & $\begin{array}{c}\text { Municipios } \\
\text { que utilizaram }\end{array}$ \\
\hline Expansão urbana em Área Rural & Americana; Itatiba \\
\hline $\begin{array}{l}\text { Expansão urbana como crescimento } \\
\text { "natural" da cidade }\end{array}$ & $\begin{array}{l}\text { Artur Nogueira; Sumaré, Monte Mor; } \\
\text { Santo Antônio da Posse }\end{array}$ \\
\hline $\begin{array}{l}\text { Áreas de expansão urbana definidas por } \\
\text { decreto ou por autorização do Executivo }\end{array}$ & Campinas \\
\hline $\begin{array}{l}\text { "Bolsões urbanos" ou expansão urbana } \\
\text { em determinados eixos de expansão }\end{array}$ & Campinas; Itatiba \\
\hline $\begin{array}{l}\text { Zonas Especiais em Áreas de Expansão } \\
\text { Urbana fora do perímetro urbano }\end{array}$ & Cosmópolis \\
\hline $\begin{array}{l}\text { Área em Zona Rural que perdeu suas } \\
\text { características produtivas }\end{array}$ & Hortolândia; Indaiatuba \\
\hline $\begin{array}{l}\text { Inclusão de área da Macrozona Rural em } \\
\text { Zona de Urbanização Específica }\end{array}$ & Itatiba \\
\hline Zona de Expansão Urbana Isolada & Itatiba \\
\hline $\begin{array}{l}\text { Loteamento aprovado em Zona Rural } \\
\text { transformado em Zona Urbana }\end{array}$ & Nova Odessa; Santa Bárbara d'Oeste; \\
\hline Loteamento em Área Rural & Jaguariúna (708/1985) \\
\hline $\begin{array}{l}\text { Parcelamento do solo "especial" em Área } \\
\text { Rural (tipo Chácaras de Recreio) }\end{array}$ & $\begin{array}{l}\text { Americana; Artur Nogueira; Hortolân- } \\
\text { dia; Indaiatuba; Itatiba; Jaguariúna } \\
\text { (97/2004); Nova Odessa; Paulínia; } \\
\text { Santa Bárbara D’Oeste; Santo Antônio da } \\
\text { Posse; Sumaré; Valinhos; Vinhedo }\end{array}$ \\
\hline Loteamento rural fechado & Campinas; Valinhos \\
\hline
\end{tabular}

Fonte: Elaboração própria (2017).

insistentemente, não são chamados de urbanos. Para além dessa figura, o município de Campinas, por exemplo, fez várias tentativas em estabelecer instrumentos legais que permitissem a implantação de núcleos urbanos em áreas rurais.

Mesmo que em alguns municípios, a legislação que institui essa modalidade fixe o tamanho mínimo do lote como o módulo mínimo do Incra para a região, a figura da chácara de recreio pode abrir horizontes para que passem a ter características urbanas se vierem a se tornar núcleos residenciais de caráter permanente, mesmo considerando as baixas densidades populacionais vinculadas, e a não necessidade de instalação de infraestrutura, mas cujo impacto é perceptível com a ampliação de serviços públicos demandados. Miranda (2002) constatou a existência destas situações em Campinas para aqueles loteamentos que foram implantados próximos ao perímetro urbano e às áreas de expansão urbana, e Freitas (2008) demonstrou que muitos em área rural (contendo lotes de tamanho igual ao módulo do Incra) possuem situações de desmembramentos irregulares, reforçando essa tendência.

\section{Contraponto ou remediação? A outra face da legislação urbanística e os dispositivos ambientais}

Da mesma forma que os planos e a legislação urbanística instituída nestes municípios possuem dispositivos ambíguos e muitas vezes permissivos em relação à ocupação das áreas rurais, há também uma outra face dessa regulamentação, que é dada pelas restrições para a expansão urbana, tornando contraditório o seu processo de planejamento. A própria instituição da lei federal de parcelamento do solo ofereceu uma barreira para que áreas externas ao perímetro urbano fossem aproveitadas para atividades urbanas, levando os municípios a definirem estratégias para driblar as pressões (de proprietários de terra) para a transformação de áreas rurais em urbanas - a delimitação de zonas de expansão urbana seria então uma saída, mas nem sempre fácil diante do desafio de estabelecê-las no âmbito dos planos diretores. É certo, porém, que a década de 1990 foi caracterizada por uma inflexão nas práticas de gestão, considerando a introdução de preocupações ambientais diante de uma nova agenda que se propagava e que foi absorvida nas normativas que passaram a ser criadas desde então, conforme se observa na Tabela 5. Se as questões ambientais no espaço urbanizado passariam a apontar por medidas específicas relacionadas, entre outras, com a complementação de obras de saneamento (como a construção de estações de tratamento de esgoto, por exemplo), recuperação de cursos d'água e criação de novos espaços verdes, nas áreas rurais, ainda não urbanizadas, seria a oportunidade de criar barreiras protecionistas para os mananciais hídricos e para a recarga hídrica, sendo recobertas por macrozonas e zonas com restrições ambientais.

No município de Campinas, a primeira lei que instituiu o loteamento fechado em áreas rurais no ano de 1974 teve que ser revogada, assim como as novas versões posteriores de 1996 e 1999 
Tabela 5 - Dispositivos ambientais na legislação urbanística dos municíios da Região Metropolitana de Campinas entre 1970 e 2006

\begin{tabular}{|c|c|c|c|c|}
\hline \multirow[b]{2}{*}{ Município } & \multicolumn{4}{|c|}{ Unidade de Conservação / instrumento } \\
\hline & 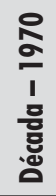 & $\begin{array}{l}\frac{\circ}{\circ} \\
\frac{1}{0} \\
\text { ㅁّㅁ }\end{array}$ & 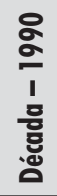 & 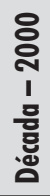 \\
\hline Americana & 1 & & 1 & 2 \\
\hline Artur Nogueira & 1 & & & 1 \\
\hline Campinas & & -1 & 3 & 4 \\
\hline Cosmópolis & & & 1 & 1 \\
\hline \multicolumn{5}{|l|}{ Eng. Coelho } \\
\hline Holambra & & & & 2 \\
\hline Hortolândia & & & 1 & 1 \\
\hline Indaiatuba & & -1 & -1 & \\
\hline Itatiba & & & 3 & 1 \\
\hline Jaguariúna & & & & 1 \\
\hline Monte Mor & & & & 3 \\
\hline Nova Odessa & & & & 3 \\
\hline Paulínia & & & 1 & 2 \\
\hline \multicolumn{5}{|l|}{ Pedreira } \\
\hline Santa Bárbara & & & & 1 \\
\hline Santo Antônio & & 2 & & \\
\hline Sumaré & & 1 & 2 & 2 \\
\hline Valinhos & & & 1 & 1 \\
\hline Vinhedo & & 2 & & 2 \\
\hline Total & 2 & 7 & 14 & 26 \\
\hline
\end{tabular}

Fonte: Elaboraç̣̃o própria (2017).

(bolsões urbanos em áreas rurais), sempre permeadas de embates envolvendo a sociedade civil, a imprensa e o Ministério Público. Ainda que tais instrumentos tenham sido banidos, foram suficientes para autorizar dezenas de loteamentos, conforme demonstrou Miranda (2002). Em outros municípios, a profusão de pedidos de loteamentos motivou várias gestões a suspender as diretrizes para abertura de novos, demonstrando a preocupação com uma expansão urbana que pudesse fugir ao controle.

Na década de 1990, a maioria dos municípios promulgou novas leis de uso e ocupação do solo, somando ao todo 19 instituídas na década. Nelas é possível perceber a introdução de mecanismos de caráter protecionista em zonas ambientais. Se o território rural ainda permanecia como parte das prerrogativas legais, os polígonos de zoneamento ambiental foram mais incisivos, determinando um novo momento na fronteira entre expansão urbana e contenção da ocupação. Como é possível observar na Tabela 5, foram progressivamente criados quase 50 tipos de áreas ambientais que resultaram na delimitação de polígonos específicos em quase todos os municípios da região. Estas delimitações incluíram desde Área de Proteção Ambiental até delimitações de bacias específicas com restrições para a urbanização, concentradas, sobretudo, nas décadas de 1990 e 2000.

Ainda que do ponto de vista institucional a criação de dispositivos ambientais tenha sido um ganho e represente, de fato, uma evolução no planejamento da expansão urbana, não quer dizer que tenha garantido, de fato, a sua contenção. 0 trabalho recente desenvolvido por Pera \& Bueno (2015) constatou que alguns municípios incluíram novas áreas em seu perímetro urbano após a instituição dos seus planos diretores na década de 2000 , ainda que tais extensões não sejam tão significativas.

\section{Considerações finais}

0 aparato institucional vinculado às formas de gestão urbana frente aos processos de urbanização recentes, e que colocam a expansão urbana como um desafio a ser enfrentado, não é uma questão de fácil resolução, nem pode ser vista a partir de um único ângulo tal como na relação estreita entre as demandas da iniciativa privada, que agregam, como agentes principais, os proprietários de terra e os empreendedores imobiliários e o controle efetivado pelo Poder Público. Como observa Dèak (1989), a dialética da forma-mercadoria não se restringe à organização do espaço, mas domina a produção e reprodução sociais, evidenciando o papel do Estado nesta contradição. Se no estágio intensivo do capitalismo essa contradição se expressava nas chamadas políticas keynesianas, no estágio avançado a negação da negação (negação, pelo Estado, da negação da forma-mercadoria), como aponta Dèak, eleva a ampliação dos mecanismos reprodutores de capital na sobreacumulação, cujo circuito passa pela produção espacial. Esta relação, vista como crucial para o entendimento das dinâmicas territoriais, como 
uma via de mão dupla, não é tão simétrica como pode parecer. A análise dos planos, enquanto formulação de um discurso de desenvolvimento urbano e da legislação urbanística autoaplicativa, enquanto instrumento efetivo de gestão, pode apresentar algumas evidências de como essa relação se estabelece, como a profusão de loteamentos potencialmente urbanos postulados como assentamentos rurais em praticamente todas as leis de parcelamento do solo dos municípios ou a partir de um excessivo legalismo e burocratismo estatal para respaldar as inúmeras transformações de áreas rurais em urbanas sem ter, necessariamente, vínculo com os planos estabelecidos. Estas especificidades reforçam as constatações de Maricato (2013) sobre a distância entre o discurso e a prática do planejamento urbano no Brasil, e de Villaça (2012) sobre o tratamento dado à lei pela sociedade brasileira no âmbito da gestão urbana.

Os mecanismos incluídos nas leis de uso, ocupação e parcelamento do solo, sedimentando uma prática ambígua na relação entre rural e urbano, foram lançados de forma bastante variada e não recrudesceram mesmo com a instituição da Lei Federal no 6766/79, que proibiu definitivamente o parcelamento do solo nas áreas rurais dos municípios. A figura da chácara de recreio é um dispositivo lançado por praticamente todos os municípios e continuou vigorando em suas leis, mesmo depois de 1979. O crescimento dos loteamentos fechados e os condomínios horizontais, que podem até representar, supostamente, uma evolução dessa tipologia, identifica-se com o modelo de dispersão, considerando a possibilidade de se implantar isoladamente sem estar necessariamente contíguo a um tecido urbano já consolidado, esbarrando, pode-se supor, nas limitações institucionais e que podem explicar, em certa medida, a contenção do grau de dispersão dos tecidos urbanos na região.

A constatações de Mitica (2008) e de Nascimento (2013) sobre a configuração das manchas urbanizadas e sua dinâmica nas últimas quatro décadas revelam aspectos importantes da evolução desse processo de urbanização - a diminuição da dispersão e, ao mesmo tempo, das áreas de expansão em toda a região a partir dos anos 1990. A área total de tecidos urbanos desconexos aos núcleos originais dos municípios diminuiu na medida em que passaram a se implantar contiguamente a estes ou a outros tecidos dispersos, contribuindo para um progressivo processo de conurbação entre alguns deles.
Mesmo sem olhar para as formas de controle do âmbito estadual que foram impostas principalmente após a Lei Federal no 6766/1979, com a obrigatoriedade do licenciamento neste âmbito e, além disso, para os mais variados mecanismos ambientais estabelecidos nas três esferas governamentais a partir dos anos 1980, como a obrigatoriedade do Estudo de Impacto Ambiental para determinados tipos de parcelamentos do solo e a instituição de unidades de conservação em escalas intermunicipais, o quadro do aparato institucional no nível municipal é uma amostra das preocupações com as restrições de caráter ambiental também nesta esfera, intensificadas nos anos 1990, mas consolidadas nos anos 2000. Se efetivaram obstáculos para essa expansão urbana e, por este motivo, cabe ainda investigar. Seja como for, não se deve descartar possíveis avanços, ainda que restritos a um arcabouço técnico-legislativo que, mesmo não refletindo as dinâmicas reais e as pressões que já têm sido sentidas com alterações de perímetros urbanos pós-planos diretores, podem estar definindo uma nova cultura de gestão urbana.

\section{Referências}

Azzoni, C. R. (1987). Indústria e reversão da polarização no Brasil (Tese de livre-docência). Faculdade de Economia e Administração, Universidade de São Paulo, São Paulo.

Baeninger, R. (2001). Região Metropolitana de Campinas: expansão e consolidação do urbano paulista. In D. J. Hogan (Ed.), Migração e ambiente nas aglomerações urbanas (1. ed., pp. 319-348). Campinas: NEPO, UNICAMP.

Brasil. (1979, 20 de dezembro). Lei $n^{\circ}$ 6.766, de 19 de dezembro de 1979. Dispõe sobre o parcelamento do solo urbano e dá outras providências. Brasília: Diário Oficial da União. Recuperado em 18 janeiro de 2017, de http:// www.planalto.gov.br/ccivil_03/leis/L6766.htm

Brasil. (2001, 11 de julho). Lei no 10.257, de 10 de julho de 2001. Regulamenta os artigos 182 e 183 da Constituição Federal, estabelece diretrizes gerais da política urbana e dá outras providências. Brasília: Diário Oficial da União. Recuperado em 18 janeiro de 2017, de http://www.planalto. gov.br/ccivil_03/leis/LEIS_2001/L10257.htm

Caiado, M. C. S. (2006). 0 verso e o reverso da dinâmica metropolitana: mobilidade populacional e estruturação 
socioespacial. In Anais do XV Encontro Nacional de Estudos Populacionais (Vol. 15, pp. 1-20). Caxambu: ABEP.

Caiado, M. C. S. (2007). Expansão recente na região metropolitana de Campinas: dispersão e novas formas urbanas. In N. G. Reis, \& M. S. Tanaka (Eds.), Brasil: estudos sobre dispersão urbana (1. ed., pp. 81-112). São Paulo: FAU-USP.

Caiado, M. C. S., \& Pires, M. C. S. (2006). Campinas Metropolitana: transformações na estrutura urbana atual e desafios futuros. In J. M. P. Cunha (Ed.), Novas metrópoles paulistas: população, vulnerabilidade e segregação (1. ed., pp. 257-304). Campinas: NEPO, UNICAMP.

Campinas. Prefeitura Municipal. (2006). Região Metropolitana: anexos da lei do Plano Diretor de 2006: cadernos de subsídios. Campinas: PMC. Recuperado em 18 janeiro de 2017, de http://campinas.sp.gov.br/governo/seplama/publicacoes/ planodiretor2006/index.php

Cano, W. (2012). A desindustrialização no Brasil. Revue Economique et Sociale, 21(4), 831-851. http://dx.doi. org/10.1590/S0104-06182012000400006.

Cano, W., \& Brandão, C. A. (2002). A região metropolitana de Campinas: urbanização, economia, finanças e meio ambiente (1. ed.). Campinas: UNICAMP.

Cunha, J. M. P. (2006). Novas metrópoles paulistas: população, vulnerabilidade, segregação (1. ed.). Campinas: NEPO, UNICAMP.

Dèak, C. (1989). O mercado e o Estado na organização espacial da produção capitalista. Espaço e Debates, 28, 18-31.

Freitas, E. L. H. (2008). Loteamentos fechados (Tese de doutorado). Faculdade de Arquitetura e Urbanismo, Universidade de São Paulo, São Paulo.

Frumkin, H. (2002). Urban sprawl and public health. Public Health Reports, 117(3), 201-217. PMid:12432132. http:// dx.doi.org/10.1016/S0033-3549(04)50155-3.

Gonçalves, M. F. (1994). Novas configurações no desenvolvimento urbano paulista. Espaços e Debates: Revista de Estudos Regionais e Urbanos, 14(38), 39-53.

Harvey, D. (2004). O novo imperialismo. São Paulo: Loyola.

Instituto Brasileiro de Geografia e Estatística - IBGE. (2017). Séries históricas e estatísticas: população presente e residente por sexo: 1970 a 2010. Brasília. Recuperado em 18 janeiro de 2017, de http://seriesestatisticas.ibge.gov. $\mathrm{br} /$ series.aspx?vcodigo=CD77
Klink, J. (Ed.) (2010). Governança das metrópoles: conceitos, experiências e perspectivas (1. ed.). São Paulo: Annablume.

Lefebvre, H. (1971). De lo rural a lo urbano (Vol. 41). Barcelona: Península.

Lencioni, S. (1994). Reestruturação urbano-industrial no Estado de São Paulo: a região da metrópole desconcentrada. In M. Santos, M. A. Souza, \& M. L. Silveira (Eds.), Território: globalização e fragmentação (4. ed., pp. 198-210). São Paulo: Hucitec.

Litman, T. (2015). Analysis of public policies that unintentionally encourage and subsidize urban sprawl. Canada: Victoria Transport Policy Institute. Recuperado em 18 janeiro de 2017, de http://static.newclimateeconomy.report/wpcontent/uploads/2015 /03/ public-policies-encouragesprawl-nce-report.pdf

Maricato, E. (2013). Brasil, cidades: alternativas para a crise urbana (7. ed.). Petrópolis: Vozes.

Miranda, Z. A. I. (2002). A incorporação de áreas rurais às cidades: um estudo de caso sobre Campinas (Tese de doutorado). Instituto de Economia, Universidade Estadual de Campinas, Campinas.

Mitica, H., No. (2008). Urbanização em Campinas: mudanças no tecido urbano no entorno da Rodovia D. Pedro I (Tese de doutorado). Faculdade de Arquitetura e Urbanismo, Universidade de São Paulo, São Paulo.

Nandin, C. L. C. (2013). Urbanização, dispersão e morfologia urbana: o eixo noroeste da Região Metropolitana de Campinas (Dissertação de mestrado). Pontifícia Universidade Católica de Campinas, Campinas.

Nascimento, E. (2013). As desigualdades socioespaciais urbanas numa metrópole interiorana: uma análise da Região Metropolitana de Campinas (SP) a partir de indicadores de exclusão/inclusão social (Tese de doutorado). Universidade Estadual de Campinas, Campinas.

Nascimento, E. (2016). Região metropolitana de Campinas (SP): cinco décadas de expansão urbana. Boletim Campineiro de Geografia, 6(1), 67-91.

Negri, B., \& Pacheco, C. A. (1994). Mudança tecnológica e desenvolvimento regional nos anos 90: a nova dimensão espacial da indústria paulista. Espaços e Debates: Revista de Estudos Regionais e Urbanos, XI(38), 62-82.

Pedroso, M. (2002). 0 desenho da ferrovia na rota do café. Oculum Ensaios, 2, 78-89. 
Pera, C. K. L., \& Bueno, L. M. M. (2015). Expansão urbana: como está sendo feita e para quem? Uma análise dos instrumentos de política urbana a partir do estudo da Região Metropolitana de Campinas-SP. In Anais do VIII Congresso Brasileiro de Direito Urbanístico (pp. 1-20). Fortaleza: IBDU.

Pereira, P. C. X., \& Sampaio, M. R. A. (1997). São Paulo, cidade global? In Anais do VII Encontro Nacional da ANPUR (pp. 1036-1053). Recife: ANPUR.

Pires, A. (2006). De rocinha aos enclaves: figurações do rural em Vinhedo, SP (Tese de doutorado). Instituto de Filosofia e Ciências Humanas, Universidade Estadual de Campinas, Campinas.

Pires, M. C. S. (2007). Morar na metrópole: expansão urbana e mercado imobiliário na Região Metropolitana de Campinas (Tese de doutorado). Instituto de Filosofia e Ciências Humanas, Universidade Estadual de Campinas, Campinas.

Reis, N. G. (2006). Notas sobre urbanização dispersa e novas formas de tecido urbano. São Paulo: Via das Artes.

São Paulo. (2000). Lei Complementar no 870, de 19 de junho de 2000. Cria a Região Metropolitana de Campinas, o Conselho de Desenvolvimento da Região Metropolitana de Campinas e autoriza o Poder Executivo a instituir entidade autárquica, a constituir o Fundo de Desenvolvimento Metropolitano da Região de Campinas, e dá providências correlatas. São Paulo: Diário Oficial do Estado. Recuperado em 18 janeiro de 2017, de http://www.al.sp.gov.br/norma/?id=5198

Soja, E. (2000). Postmetropolis: critical studies of cities and regions. Oxford: Blackwell.

Souza, M. A. (2010). O II PND e a política urbana brasileira: uma contradição evidente. In C. Deák, \& S.R. Schiffer (Eds.), O processo de urbanização no Brasil (2. ed., pp. 111-144). São Paulo, EDUSP.

Sumaré. (1977). Lei no 1.361, de 1 de agosto de 1977. Inclui na Zona de Expansão Urbana do município de Sumaré, imóveis que especifica e dá outras providências. Sumaré: Prefeitura do Município de Sumaré.

Villaça, F. (2012). Reflexões sobre as cidades brasileiras (1. ed.). São Paulo: Nobel.

Vizioli, S. H. T. (1998). Planejamento urbano no Brasil: a experiência do SERFHAU enquanto órgão federal de planejamento integrado ao desenvolvimento municipal (Dissertação de mestrado). Faculdade de Arquitetura e Urbanismo, Universidade de São Paulo, São Paulo.

Recebido: Jan. 31, 2017

Aprovado: Maio 19, 2017 